\title{
Economic and socio-environmental performance assessment of beef cattle production systems: a data envelopment analysis (DEA) approach with weight restrictions
}

\section{Eliane Gonçalves Gomes', Urbano Gomes Pinto de Abreu², João Carlos Correia Baptista Soares de Mello ${ }^{3}$, Thiago Bernardino de Carvalho ${ }^{4}$, Sergio de $\mathrm{Zen}^{4}$}

\author{
1 Embrapa Sede, Brasilia, DF, Brasil. \\ ${ }^{2}$ Embrapa Pantanal, Corumbá, MS, Brasil. \\ ${ }^{3}$ Universidade Federal Fluminense, Departamento de Engenharia de Produção, Niterói, RJ, Brasil. \\ ${ }^{4}$ Escola Superior de Agricultura "Luiz de Queiroz", Centro de Estudos Avançados em Economia Aplicada, Piracicaba, SP, Brasil.
}

\begin{abstract}
This study evaluated the performance of 21 beef cattle modal production systems that conduct only the raising phase. These production systems were developed in 21 municipalities in seven Brazilian states. We used two different DEA BCC models, corresponding to different points of view. Firstly we used an economic model that measured the ability of a production system to generate revenue with the preservation of native forest, using labor, capital, and current spending as inputs. The socio-environmental approach, corresponding to the second BCC model, uses the production factor labor as an output. In that model our interest was to assess whether the capital costs generate economic, environmental, and social benefits. Weight restrictions were imposed on the output variables of each model to explain the proposed viewpoints and to avoid inconsistent results. The results pointed out sources of inefficiency in terms of labor with low qualification, and use of bulls of questionable quality, factors that are common in extensive systems. These are some of the major bottlenecks in animal production systems as a whole.
\end{abstract}

Key Words: animal production, beef cattle raising systems, efficiency models

\section{Introduction}

The Brazilian beef production chain has been consolidated as an important component of the production and the international trade: Brazil is currently the largest exporter (25\% of world total) and the second largest producer of beef (accounting for 14\% of total) (ANUALPEC, 2010). The national herd comprises about 176,610,950 animals, according to ANUALPEC (2010), which represents $17 \%$ of the world cattle herd and an increase of $6 \%$ in relation to the figure recorded in the country in 2001. Another aspect that corroborates this scenario is the share of this industry in the gross domestic product (GDP): in 2008, 8\% was from livestock (CEPEA, 2012). If we consider only the agricultural GDP, 38\% came from livestock. Thus, the study and the evaluation of beef cattle production systems are important elements to enhance the performance of the sector.

\footnotetext{
Received November 6, 2014 and accepted April 7, 2015

Corresponding author: urbano.abreu@embrapa.br

http://dx.doi.org/10.1590/\$1806-92902015000600004
}

Copyright $\odot 2015$ Sociedade Brasileira de Zootecnia. This is an Open Access article distributed under the terms of the Creative Commons Attribution Non-Commercial License, which permits unrestricted non-commercial use, distribution, and reproduction in any medium, provided the original work is properly cited.
The central structure in the beef cattle production chain is the biological system of beef production, which includes the different stages of rearing (cow-calf production $\mathrm{CCP}$, stocker production, feedlot beef production) and their combinations, around which the ranchers are grouped (Cardoso, 1994). In Brazil, the CCP phase occurs predominantly in extensive continuous grazing, with native and/or cultivated pastures, and encompasses calves (until weaning or even one year of age), cows, heifers, and bulls. This is both the least profitable and the most risky activity. However, it supports the entire structure of the beef cattle production chain.

The objective of this study was to evaluate the performance of some beef cattle farming systems that specialize in the CCP phase. The raising systems are the basis for the entire beef cattle production chain. The management and the process improvement in this phase should be reflected in enhanced production efficiency of the entire chain. The modal production systems were defined in debates carried out in the main Brazilian cities in which beef cattle raising systems are developed.

We used data envelopment analysis (DEA) models with weight restrictions to measure the efficiency of the systems from two viewpoints: economic and socioenvironmental. The different weight restrictions used in 
the different modeling approaches involve a technique similar to that used by Gomes et al. (2009), who studied the agricultural sustainability of a group of farmers in the Brazilian Amazon.

The objective of our model is to measure the performance of beef cattle production systems that are specialized in the CCP phase. The decision making units (DMU) are the 21 modal production systems identified from the discussion panels in 21 municipalities in seven Brazilian states.

\section{Material and Methods}

Primary data were collected through the panel system. This technique enables the definition of representative farms that are defined by Plaxico and Tweeten (1963) as the ideal approach when studying rural production units.

Despite the difficulty in characterizing a single property and a production system that is representative of the locality under study (here, the city), the method seeks to feature the property that is the most commonly found in the region, through the experience of the participating farmers. In some cases, the impossibility of determining the typical farm requires the definition of more than one property or production system to be represented. The panel follows, in short, four steps: Survey of technical production coefficients and regional information; Visit to the properties; Preparation of spreadsheets; and Panel execution.

The panel is a procedure for obtaining information that is less costly than the census or the sample survey of farms. Another advantage is that it provides flexibility and versatility in data updating, without compromising their quality. The technique consists of a meeting with a group of one or more researchers, a technician, and a group of farmers (eight, on average, ranging from five to ten). Meetings are scheduled in advance, frequently using the trade unions and rural regional contacts. The themes and figures previously determined in interviews with the local technicians are discussed with the farmers.

The researchers use portable computers and a device designed to project the spreadsheets previously created (step (3)), so that all participants can interact. Different technical coefficients, prices, and frequency of use are presented to the group, which discusses and improves the information. At the end of the discussion, we can say that the characterization of the typical regional farm is endorsed by the farmers. Therefore, the productivity rates, costs of implementation, fixed and variable costs, i.e., all the figures resulting from the panel, tend to be quite close to the regional reality.
The rates and the costs reported by each participant are not related to their respective properties, but refer to a single farm, declared at the beginning of the panel as the one that best represents the size and the production systems of most local rural properties.

Our study evaluated 21 beef cattle modal production systems that performed only the CCP stage, in seven states in Brazil. The data are from the Livestock Project Indicators and were collected in the following states: Mato Grosso do Sul - MS (eight), Goiás - GO (four), Rio Grande do Sul RS (one), Minas Gerais - MG (four), Tocantins - TO (two), São Paulo - SP (one), and Bahia - BA (one). Panels were conducted with farmers and local technical assistance for data collection, according to the methodology described in the Centro de Estudos Avançados em Economia Aplicada's report (CEPEA, 2010).

Data envelopment analysis is an efficiency assessment approach based on linear programming problems. Its aim is to calculate the efficiency of productive units, called decision making units (DMU), after knowing the used resources and the obtained results. Data envelopment analysis optimizes each individual observation, in order to estimate an efficient frontier (piecewise linear) composed of the units with the best practices within the sample under evaluation (Pareto-Koopmans efficient units). These units are references or benchmarks for inefficient units.

The two most commonly known DEA models are the CCR and the BCC (Cooper et al., 2004). The CCR model assumes the constant returns to scale hypothesis (axiom of proportionality). The BCC model considers variable returns to scale (axiom of convexity). Two radial directions are possible for these models: input-oriented (attempts to reduce the resources while maintaining the production levels) and output-oriented (seeks to maximize the products with the quantities of inputs remaining unchanged). Non-radial orientations are possible in advanced models (Gomes Junior et al., 2013).

Models (1) and (2) represent the DEA BCC multipliers (a) and envelope (b) models, input- and output-oriented, respectively.

$$
\begin{aligned}
& \operatorname{Max} E f f_{o}=\sum_{j} u_{j} y_{j o}-u^{*} \\
& \text { s.t. } \\
& \sum_{i} v_{i} x_{i o}=1 \\
& -\sum_{i} v_{i} x_{i o}+\sum_{j} u_{j} y_{j o}-u^{*} \leq 0, \forall k \\
& u, v \geq 0, u^{*} \in \mathfrak{R}
\end{aligned}
$$

$$
\begin{aligned}
& \operatorname{Min} \quad h_{o} \\
& \text { s.t. } \\
& h_{o} x_{i o}-\sum_{k} x_{i k} \lambda_{k} \geq 0, \forall i \\
& -y_{j o}+\sum_{k} y_{j k} \lambda_{k} \geq 0, \forall j \\
& \sum_{k} \lambda_{k}=1 \\
& \lambda_{k} \geq 0, \forall k
\end{aligned}
$$




$$
\begin{array}{ll}
\text { Min } E f f_{o}=\sum_{i} v_{i} x_{i o}-v^{*} & \operatorname{Max} h_{o} \\
\text { s.t. } & \text { s.t. } \\
\sum_{j} u_{j} y_{j o}=1 & x_{i o}-\sum_{k} x_{i k} \lambda_{k} \geq 0, \forall i \\
-\sum_{i} v_{i} x_{i o}+\sum_{j} u_{j} y_{j o}+v^{*} \leq 0, \forall k & -h_{o} y_{j o}+\sum_{k} y_{j k} \lambda_{k} \geq 0, \forall j \\
u, v \geq 0, v^{*} \in \mathfrak{R} & \sum_{k} \lambda_{k}=1 \\
& \lambda_{k} \geq 0, \forall k
\end{array}
$$

In formulations (1a) and (2a), eff is the efficiency of the DMUo under analysis; $x_{i k}$ represents the input $i$ of DMU $k$; $y_{j k}$ is the output $j$ of DMU $k ; v_{i}$ is the weight for input $i$; $u_{j}$ is the weight for output $j ; x_{i o}$ and $y_{j o}$ are the input $i$ and the output $j$ of the DMUo, respectively; and $u^{*}$ and $v^{*}$ are the scaling factors (when positive, they indicate decreasing returns to scale; negative factors mean increasing returns to scale; null values indicate constant returns to scale).

In (1b) and (2b), $h_{o}$ is the efficiency of the DMU under analysis.

Note that the linear programming problems (a) and (b) are dual, and thus have the same objective function optimal value. $\lambda_{k}$ is the contribution of DMU $k$ in the formation of the target of DMUo (DMU with the non-zero $\lambda_{k}$ are the benchmarks of the DMUo). The CCR models, input- and output-oriented in their primal and dual versions, can be obtained from models (1) and (2), by removing the convexity constraint in the envelope formulation $\left(\sum \lambda_{k}=1\right)$ and the scaling factors in the multipliers formulation.

In order to model and to interpret the DEA results correctly it is necessary to know the properties of these models. Two of the most important are (Gomes et al., 2009): (1) In any DEA model, the DMU that has the best value of the ratio will always be efficient. This property requires verifying the existence of a causal relationship between each input and each output. Failures in these relationships can lead to meaningless results. (2) The CCR model has the main property of proportionality between inputs and outputs at the frontier. As a result, the increase (decrease) in the quantity of inputs will cause a proportional increase (decrease) in the outputs value.

The use of DEA models to evaluate the efficiency of beef cattle production systems is recent in the literature. We can cite, for example, the works of Chaminuka et al. (2014), Ceyhan and Hazneci (2010), and Ruiz et al. (2000). In the specific case of beef cattle in Brazil, Abreu et al. (2006) analyzed the efficiency of a cattle production system in the Pantanal biome in Corumbá, in which technologies were implemented over eight years (1995-2002). The authors considered information on ten categories of spending on inputs and a product category. With the same economic data recorded during the abovementioned period, Abreu et al. (2008) used different DEA variable selection approaches to conduct their study. Two models were run (with six inputs and one output, and with three inputs and one output) and the efficiency results were analyzed based on the classical and inverted DEA frontiers, besides the value of the composite index that combines both results. Other examples of DEA use in Brazilian beef cattle production can be seen in Gomes et al. (2012) and Abreu et al. (2012). Some recent uses of DEA in agriculture as a whole may be found, for instance, in Aldanondo-Ochoa et al. (2013), Bojnec and Latruffe (2013), Falavigna et al. (2013), Novo et al. (2013), and Sánchez-Zamora et al. (2014).

The classic DEA models allow for complete freedom in calculating the weights that maximize the efficiency value of the DMU under analysis. This freedom is important in the identification of the inefficient units, i.e., those which have poor performance even with their own set of multipliers.

The abovementioned flexibility in choosing the weights is one of the advantages linked to the DEA modeling. However, the calculated weights may be inconsistent with the knowledge about the relative values of inputs and outputs. Thus, the incorporation of experts' value judgments about the relative importance of each variable in the calculation of efficiency measures emerges as a natural evolution of the DEA applications to real problems. That means it is necessary to introduce conditions besides those of weight non-negativity.

When there are preferences between the inputs and/or outputs, these decision-maker judgments are incorporated into the DEA models using weight restrictions associated with the inputs and/or outputs. Allen et al. (1997) and Thanassoulis et al. (2004) present a review of the evolution of the incorporation of value judgments by weight restrictions. Angulo Meza and Lins (2002) consider that the addition of weight restrictions is one of the techniques that promote improvement of discrimination in DEA, adding subjective opinions. Adler et al. (2002) also include restrictions on the weights within the group of techniques that improve discrimination in DEA, and propose different types of restrictions. The main ones are: direct restrictions on the multipliers, adjusting the input-output levels observed to capture the value judgments, and restricting the virtual inputs and outputs.

The Assurance Region Type I (ARI) is one of the proposed weight restrictions approaches, as defined by Thompson et al. (1990). In model (3) we show the generic formulation of the BCC model with output ARI restrictions imposed, where $\alpha_{i}$ and $\beta_{i}$ are constants specified by the 
decision-maker and, after a suitable normalization, they reflect the value judgments about the relative importance between the outputs $j$ and $j+1$.

$$
\begin{aligned}
& \operatorname{Max} \sum_{\mathrm{j}} u_{j} y_{j o}-u^{*} \\
& \text { s.t. } \\
& \sum_{i} v_{i} x_{i o}=1 \\
& -\sum_{i} v_{i} x_{i k}+\sum_{j} u_{j} y_{j k}-u^{*} \leq 0, \forall k \\
& \alpha_{j} \leq \frac{u_{j}}{u_{j+1}} \leq \beta_{j} \\
& u_{j}, v_{i} \geq 0, \forall j, i \quad u^{*} \in \Re
\end{aligned}
$$

where $x_{i k}$ represents the input $i$ of DMU $k ; y_{j k}$ is the output $j$ of DMUk; $v_{i}$ is the weight for input $i ; u_{j}$ is the weight for output $j ; x_{i o}$ and $y_{j o}$ are the input $i$ and the output $j$ of the DMU $o$, respectively; and $u^{*}$ and $v^{*}$ are the scaling factors (when positive, they indicate decreasing returns to scale; negative factors mean increasing returns to scale; null values indicate constant returns to scale).

It should be noted that by imposing the ARI weight restrictions type, if one aims to to measure the importance assigned by each DMU to each variable, the data should be normalized. This prevents the weights values from being influenced by the scale of the data. Although in this article, regarding the multipliers' formulation, we are only interested in evaluating the efficiency measure and the number of zero weights assigned to the variables, the variables were normalized to avoid misinterpretation of the results. The inputs of the economic model were "labor" (quantity of employees), "area of pasture" (hectares), "spending on buying animals" (Brazilian currency, BRL), and "other expenses" (supplementation, administrative expenses, maintenance of pastures, maintenance of buildings and improvements, utilities; BRL). The outputs were "area for conservation of native forest" (hectares) and "livestock gross revenue" (BRL).

In the model that aims to measure the socioenvironmental performance, the selected inputs were "area of pasture" (hectares) and "spending on buying animals (BRL)" and the outputs were "labor" (quantity of employees), "area for conservation of native forest" (hectares), and "livestock gross revenue" (BRL).

The economic model measures the ability of each production system to generate revenue while preserving the native forest, by using factors of production such as labor, capital and current spending. In this model, an additional restriction was imposed: that the weight of the "livestock revenue" variable must be greater than the weight of the "area for conservation" variable. The use of weight restriction prevents a production system that only preserves native forest without generating revenues from becoming efficient.

In the socio-environmental performance model the production factor "labor" is an output. In this model we are interested in studying whether capital (land) and costs generate economic (income), environmental (preservation of native vegetation), and social (jobs generation) benefits. In this model we also added two ARI-type weight restrictions: the weight of the "labor" variable must be greater than the weight of the "livestock revenue" variable, and the weight of the "area for conservation" variable must be greater than the weight of the "livestock revenue" variable. These weight restrictions prevent a DMU from being efficient only due to good economic performance; the DMU must have good social or environmental performances to be efficient under this assessment.

In this paper we used the DEA BCC model, since there was no evidence of proportionality between inputs and outputs, and the scales of production are known to be different among the various modal systems. We chose output-oriented models, since the goal is to evaluate the model performance concerning economic and socioenvironmental variables that are the outputs in both models. In each proposed model the output variables have different importance, according to the adopted viewpoint. This feature can be inserted into DEA models by weight restrictions, as previously discussed. Another reason for the use of weight restrictions is the fact that in extreme cases there may be efficient units without preservation or production. This may occur due to the DEA models' benevolence, in particular the DEA BCC. These extreme situations appear due to the possibility of assigning zero weight to any output in the classic DEA models.

As previously described, in the economic model it was imposed that the weight of the "livestock revenue" variable must be greater than the weight of the "area for conservation" variable. In the socio-environmental model the weight restrictions were: the weight of "labor" must be greater than the weight of "livestock revenue" and the weight of "area for conservation" must be greater than the weight of "livestock revenue".

\section{Results}

The modal production systems practiced in Aquidauana, Bonito, Brasilândia, Carlos Chagas, Corumbá, Lavras 
do Sul, Tupã, and Uberlândia were efficient in both approaches (Table 1). Catalão, Itamarajú, Niquelândia, and Rio Verde were efficient in the economic model but not in the socio-environmental one. Camapuã, Montes Claros, and São Gabriel do Oeste were efficient only in the socio-environmental model. The remaining systems were ineffective from both points of view.

The systems that were efficient in the two approaches are characterized by two patterns. The first group (Aquidauana, Brasilândia, Carlos Chagas, and Corumbá) is characterized by the scale of livestock production systems with higher revenue. The second group (Bonito, Lavras do Sul, Tupã, and Uberlândia), although characterized by a smaller scale, have higher values of the revenue/area of pastures ratio. All these production systems have significant shares of areas for conservation, except for Brasilândia.

The production systems of Catalão, Itamarajú, Niquelândia, and Rio Verde are characterized as medium to small areas of pasture, and high-income in relation to the area of pasture. These are typical intensive raising production systems.

The systems that were more efficient from the socioenvironmental perspective have increased revenues in relation to the total size of the conservation area (Camapuã and Montes Claros). In parallel, the production system of São Gabriel do Oeste shows a high percentage of conservation area in relation to the area of pasture.

Brasilândia is an interesting case. Despite presenting a zero value for the area of conservation, it was efficient in the socio-environmental model. This can be explained

Table 1 - Efficiency scores

\begin{tabular}{lcc}
\hline DMU & Economic model & Socio-environmental mode \\
\hline Alvorada & 0.978 & 0.901 \\
Amanbaí & 0.769 & 0.881 \\
Aquidauana & 1.000 & 1.000 \\
Bonito & 1.000 & 1.000 \\
Brasilândia & 1.000 & 1.000 \\
Camapuã & 0.974 & 1.000 \\
Carlos Chagas & 1.000 & 1.000 \\
Catalão & 1.000 & 0.818 \\
Corumbá & 1.000 & 1.000 \\
Itamarajú & 1.000 & 0.617 \\
Lavras Sul & 1.000 & 1.000 \\
Montes Claros & 0.854 & 1.000 \\
Niquelândia & 1.000 & 0.716 \\
Paraíso do Tocantins & 0.819 & 0.717 \\
Porangatu & 0.827 & 0.589 \\
Ribas do Rio Pardo & 0.720 & 0.828 \\
Rio Verde & 1.000 & 0.677 \\
São Gabriel do Oeste & 0.985 & 1.000 \\
Tupã & 1.000 & 1.000 \\
Uberaba & 0.783 & 0.959 \\
Uberlândia & 1.000 & 1.000 \\
\hline
\end{tabular}

DMU - decision-making unit. by the fact that the production system developed there uses a greater amount of labor in relation to its size, i.e., it has good social performance but poor environmental performance. The weight restrictions that were used allow a DMU to have a good performance in only one of these factors, and prevent the DMU from being good economic performers but poor social or environmental performers.

\section{Discussion}

In both models, the production systems are operating under increasing returns to scale. In the socio-environmental model, Uberlândia operates with constant returns to scale. In all raising systems it can be inferred that the balanced addition of inputs could lead to improved results. This is probably because the CCP stage is believed to be the phase with the lowest revenue (Euclides Filho, 1997). Thus, in general, investments in productivity are conservative to avoid economic risks. On the other hand, structural modifications can result in the transformation of a sector characterized by inefficiency in management in a rural business able to establish controls, allowing the calculation of livestock and economic indicators (Oaigen et al., 2009).

In the economic model, the modal production systems of Catalão and Bonito were the most referenced as benchmarks (ten and nine times, respectively). In the socioenvironmental model, Catalão was the most commonly reported benchmark (nine times). Both municipalities had high revenue levels, with small areas of pastures and relatively large areas of conservation, which indicates efficient management with consequent high productivity.

Regarding the structure of the weights (or multipliers), the "labor" and "spending on buying animals" variables received zero weight in 62 and $57 \%$ of cases, respectively, in the economic model. This means that in most production systems the employment of labor and the expenses of purchasing bulls are not suited to the obtained production levels (these should be higher). This may be the result of poor management of the bulls' herd or a purchase of bulls of questionable breeding value, which, coupled with the lower workforce qualification in the extensive systems in general, generates a bottleneck in the development of the animal husbandry as a whole. In the socio-environmental model, the largest amount of zero weights was assigned to the "livestock gross revenue" and "spending on buying animals" variables (62 and 38\% respectively). In the output case, assigning zero weights may be linked to the weight restrictions added to this model. As for the input, this result confirms the previous discussion, in the sense that the costs of purchasing bulls are higher than desired. 
On the other hand, there is a need to perform dynamic studies that imply the incorporation of time in analytical frameworks of the CCP system's economic and socioenvironmental sustainability. We need to know the main determinants of the CCP system evolution and how the resilience and adaptability of beef cattle systems can be enhanced to cope with the uncertainty and variability of the physical and economical environment (Bernués et al., 2011).

\section{Conclusions}

When analyzing the benchmarks, we noticed that the two most referenced municipalities have significant levels of revenue, with small areas of pastures and relatively large areas for conservation, which are indicators of management efficiency, with consequent high productivity of the systems.

The approach used enabled the identification of sources of inefficiencies due to workforce with low qualification and the use of bulls of questionable quality, a common situation in extensive systems and one of the major bottlenecks in the livestock systems as a whole.

\section{Acknowledgments}

To Embrapa and CNPq for their financial support, and to CEPEA/CNA for providing the data for analysis.

\section{References}

Abreu, U. G. P.; Gomes, E. G.; Lopes, P. S.; Torres, R. A. and Santos, H. N. 2008. A systemic evaluation of introduction of technology in beef cattle production system in Pantanal wetlands by data envelopment analysis (DEA) models. Revista Brasileira de Zootecnia 37:2069-2076.

Abreu, U. G. P.; Gomes, E. G.; Soares de Mello, J. C. C. B.; Santos, S. A. and Catto, D. F. 2012. Heifer Retention Program in the Pantanal: a study with data envelopment analysis (DEA) and Malmquist index. Revista Brasileira de Zootecnia 41:1937-1943.

Abreu, U. G. P.; Lopes, P. S.; Baptista, A. J. M. S.; Torres, R. A. and Santos, H. N. 2006. Evaluation of technology introduction in a beef cattle production system in Pantanal wetlands. Analysis of efficiency. Revista Brasileira de Zootecnia 35:1242-1250.

Adler, N.; Friedman, L. and Sinuany-Stern, Z. 2002. Review of ranking methods in the data envelopment analysis context. European Journal Operational Research 140:249-265.

Aldanondo-Ochoa, A. M.; Casasnovas-Oliva, V. L. and ArandiaMiura, A. 2013. Environmental efficiency and the impact of regulation in dryland organic vine production. Land Use Policy 36:275-284.

Allen, R.; Athanassopoulos, A.; Dyson, R. G. and Thanassoulis, E. 1997. Weights restrictions and value judgments in data envelopment analysis: evolution, development and future directions. Annals of Operations Research 73:13-34.
Angulo Meza, L. and Lins, M. P. E. 2002. Review of methods for increasing discrimination in data envelopment analysis. Annals of Operations Research 116:225-242.

ANUALPEC - Anuário da Pecuária Brasileira. 2010. Agra FNP Pesquisas, São Paulo.

Bernués, A.; Ruiz, R.; Olaizola, A.; Villalba, D. and Casasús, I. 2011. Sustainability of pasture-based livestock farming systems in the European Mediterranean context: Synergies and trade-offs. Livestock Science 139:44-57.

Bojnec, S. and Latruffe, L. 2013. Farm size, agricultural subsidies and farm performance in Slovenia. Land Use Policy 32: 207-217.

Cardoso, E. G. 1994. A cadeia produtiva da pecuária bovina de corte. Embrapa Gado de Corte. Série Documentos, 49. Embrapa Gado de Corte, Campo Grande.

CEPEA - Centro de Estudos Avançados em Economia Aplicada. 2010. Metodologia do índice de preços dos insumos utilizados na produção pecuária brasileira. Available at: $<$ http://www.cepea. esalq.usp.br/boi/metodologiacna.pdf>. Accessed on: Sep. 15, 2014.

CEPEA - Centro de Estudos Avançados em Economia Aplicada. 2012. PIB do Agronegócio. Available at: <http://www.cepea.esalq.usp. br/pib/>. Accessed on: Sep. 15, 2012.

Ceyhan, V. and Hazneci, K. 2010. Economic efficiency of cattlefattening farms in Amasya Province, Turkey. Journal of Animal and Veterinary Advances 9:60-69.

Chaminuka, P.; Udo, H. M. J.; Eilers, K. C. H. A. M. and van der Zijpp, A. 2014. Livelihood roles of cattle and prospects for alternative land uses at the wildlife/livestock interface in South Africa. Land Use Policy 38:80-90.

Cooper, W. W.; Seiford, L. M. and Zhu, J. 2004. Handbook on data envelopment analysis. Kluwer Academic Publishers, Boston.

Euclides Filho, K. 1997. A pecuária de corte no Brasil: novos horizontes, novos desafios. Série Documentos, 69. Embrapa Gado de Corte, Campo Grande.

Falavigna, G.; Manello, A. and Pavone, S. 2013. Environmental efficiency, productivity and public funds: The case of the Italian agricultural industry. Agricultural Systems 121:73-80.

Gomes Junior, S. F.; Soares de Mello, J. C. C. B. and Angulo Meza, L. 2013. DEA non-radial efficiency based on vector properties. International Transactions in Operational Research 20:341-364.

Gomes, E. G.; Abreu, U. G. P.; Soares de Mello, J. C. C. B.; Carvalho, T. B. and Zen, S. 2012. Unitary input DEA model to identify beef cattle production systems typologies. Pesquisa Operacional $32: 389-406$

Gomes, E. G.; Soares de Mello, J. C. C. B.; Souza, G. S.; Angulo Meza, L. and Mangabeira, J. A. C. 2009. Efficiency and sustainability assessment for a group of farmers in the Brazilian Amazon. Annals of Operations Research 169:167-181.

Novo, A. M.; Slingerland, M.; Jansen, K.; Kanellopoulos, A. and Giller, K. E. 2013. Feasibility and competitiveness of intensive smallholder dairy farming in Brazil in comparison with soya and sugarcane: Case study of the Balde Cheio Programme. Agricultural Systems 121:63-72.

Oiagen, R. P.; Barcellos, J. O. J.; Christofari, L. F.; Braccini Neto, J.; Oliveira, T. E. and Prates, E. R. 2009. Análise da sensibilidade da metodologia dos centros de custos mediante a introdução de tecnologias em um sistema de produção de cria. Revista Brasileira de Zootecnia 38:1155-1162.

Plaxico, J. S. and Tweeten, L. G. 1963. Representative farms for policy and projection research. Journal of Farm Economics 45:1458-1465.

Ruiz, D. E. M.; Pardo Sempere, L.; García Martínez, A. A.; Rodríguez Alcaide, J. J.; Pamio, J. O.; Pena Blanco, F. and Domenech, G. 2000. Technical and allocative efficiency analysis for cattle fattening on Argentina Pampas. Agricultural Systems 65:179-199. 
Sánchez-Zamora, P.; Gallardo-Cobos, R. and Ceña-Delgado, F. 2014. Rural areas face the economic crisis: Analyzing the determinants of successful territorial dynamics. Journal Rural Studies 35:11-25.

Thanassoulis, E.; Portela, M. C. S. and Allen, R. 2004. Incorporating value judgments in DEA. p.99-138. In: Handbook on data envelopment analysis. Cooper, W. W.; Seiford, L. M. and Zhu, J., eds. Kluwer Academic Publishers, Boston.

Thompson, R. G.; Langemeier, L. N.; Lee, C. T.; Lee, E. and Thrall, R. M. 1990. The role of multiplier bounds in efficiency analysis with application to Kansas farming. Journal Econometrics 46:93-108. 